\title{
JHouve LHomme
}

Revue française d'anthropologie

226 | 2018

Varia

Bernard Formoso, ed., Sociétés civiles d'Asie du SudEst continentale. Entre pilotage d'État et initiatives citoyennes

Lyon, ENS Éd., 2016, 285 p., notes bibliogr., index, ill. ("De l'Orient à l'Occident").

Olivier Evrard

\section{CpenEdition}

Journals

Édition électronique

URL : http://journals.openedition.org/lhomme/31991

DOI : ERREUR PDO dans /localdata/www-bin/Core/Core/Db/Db.class.php L.34 : SQLSTATE[HYO00]

[2006] MySQL server has gone away

ISSN : 1953-8103

Éditeur

Éditions de l'EHESS

Édition imprimée

Date de publication : 20 juin 2018

Pagination : 201-202

ISBN : 978-2-7132-2734-9

ISSN : 0439-4216

Référence électronique

Olivier Evrard, «Bernard Formoso, ed., Sociétés civiles d'Asie du Sud-Est continentale. Entre pilotage d'État et initiatives citoyennes », L'Homme [En ligne], 226 | 2018, mis en ligne le 20 juin 2018, consulté le 08 janvier 2021. URL : http://journals.openedition.org//homme/31991 ; DOI : https://doi.org/10.4000/ Ihomme.31991

Ce document a été généré automatiquement le 8 janvier 2021.

(c) École des hautes études en sciences sociales 


\title{
Bernard Formoso, ed., Sociétés civiles d'Asie du Sud-Est continentale. Entre pilotage d'État et initiatives citoyennes
}

\author{
Lyon, ENS Éd., 2016, 285 p., notes bibliogr., index, ill. ("De l'Orient à
}

l'Occident").

Olivier Evrard

\section{RÉFÉRENCE}

Bernard Formoso, ed., Sociétés civiles d'Asie du Sud-Est continentale. Entre pilotage d'État et initiatives citoyennes, Lyon, Ens Éd., 2016, 285 p., notes bibliogr., index, ill. ("De l'Orient à l'Occident").

1 Durant les années 1990, un fort enthousiasme avait accompagné l'expansion de la société civile en Asie du Sud-Est. En effet, l'optimisme suscité par les initiatives des groupes de citoyens militants et des Organisations non gouvernementales dans différents pays confortait beaucoup d'analystes dans l'idée qu'avec l'émergence de classes moyennes urbanisées, une vague de démocratisation était en train de renouveler profondément le paysage politique, soutenue par un capitalisme triomphant, pour lequel la crise de 1997 n'était finalement qu'une péripétie. Deux décennies plus tard, l'optimisme a laissé place à un certain désenchantement. L'autoritarisme des régimes sud-est asiens n'a pas été perturbé par l'émergence d'une société civile et semble même s'en être nourri dans certains cas, comme en témoigne l'actualité récente au Cambodge ou en Thaillande.

2 Ce retournement de perspective impose un double travail de réflexion. Le premier relève de l'anthropologie politique : il devient urgent de repenser le concept de société civile en le détachant de celui de démocratie, c'est-à-dire en dehors de son prisme individualiste, libéral et séculier. Le second concerne davantage l'histoire contemporaine : il s'agit d'étudier et d'interpréter l'actualité politique de ces pays pour 
comprendre à la fois la pérennité des formes de pouvoir et leurs mutations et contestations. C'est à cette double tâche que s'attelle l'ouvrage, en conjuguant avec succès les questionnements et les apports de l'anthropologie et de la science politique, et en dressant, en trois parties et six chapitres, un état des lieux de la société civile sudest asienne à travers différents contextes nationaux.

3 La première partie souligne la difficile conciliation du parlementarisme et des prérogatives des élites statutaires. En Thaïlande, celles-ci sont organisées autour d'un pôle associant la monarchie, le clergé et les militaires, dont les liens se sont renforcés au cours de la dernière décennie. L'impossibilité de contredire les structures hiérarchiques et clientélistes dans l'espace public imprègne aussi les relations entre les classes à fort capital social et les autres. Ainsi s'explique la défiance des cols blancs et de nombreux représentants d'ONG locales envers les systèmes électoraux donnant une voix égale à tous, de même que leur soutien affiché au coup d'État de 2014. Ce dernier a permis l'instauration d'une dictature militaire pendant une phase de "transition " toujours en cours. Au Myanmar, la recherche d'un compromis entre militaires et parlementaires opère dans un contexte très différent, en raison d'un système territorial fédéral et de l'existence de nombreux mouvements irrédentistes à base ethnique. À ce tableau complexe s'ajoute une multitude d'associations et d'ONG, internationales et birmanes, religieuses ou laïques, certaines en lien direct avec les mouvements autonomistes, d'autres pilotées en sous-main par la junte, d'autres enfin représentant des exilés birmans. Il en résulte une prolifération «d'isolats de société civile » (p. 88), évoluant selon leurs propres agendas dans une cacophonie qui fait l'affaire des autocrates et ne les empêche aucunement, comme le montre l'exemple récent des Rohingya, d'exalter les passions clivantes au détriment d'un projet fédérateur.

4 La deuxième partie illustre, à partir des contextes cambodgien et malaisien, comment des formations politiques hégémoniques cherchent à maintenir leur pouvoir par tous les moyens. Au Cambodge, le régime ploutocrate d'Hun Sen verrouille aujourd'hui les consultations électorales, réprime durement toute contestation, contrôle les médias et les ONG nationales, et, dans le même temps, utilise les codes symboliques de la société khmère pour se poser en garant de l'ordre social. La multiplication des ONG et l'ouverture politique des années 1990 n'ont donc pas abouti à un système démocratique inspiré des codes occidentaux : de ce point de vue, les dernières années constituent plutôt (au Cambodge comme en Thaillande) des retours en arrière. En Malaisie, la société civile est morcelée en sous-sphères ethniques (Malais, Hindous et Chinois), élaborant chacune la meilleure stratégie pour défendre ses intérêts, avec un rôle prééminent joué par l'organisation représentant les Malais musulmans. Depuis l'indépendance, quelques mouvements ont pu transcender ponctuellement ces clivages ethniques, mais aucun n'a véritablement débouché sur des réformes constitutionnelles. Comme en Birmanie, mais dans un contexte tout autre, la société civile reste donc éclatée en sphères ethnico-religieuses, " générant un vivre-à-côté, et même un vivre contre, plutôt qu'un vivre ensemble » (p. 273).

5 Les e-medias et le cyberespace, dont le rôle est étudié dans la troisième partie de l'ouvrage, n'ont pas, jusqu'à présent, offert un nouvel espace de subjectivation politique. Que ce soit en Thaillande, à Singapour, en Malaisie ou en Indonésie, ils permettent parfois une expression libérée des contraintes hiérarchiques, mais peuvent aussi amplifier les haines intercommunautaires ou servir les intérêts de l'économie de marché en valorisant les comportements consuméristes. Par ailleurs, on y observe 
également une pratique fréquente de l'autocensure, en raison de la surveillance de la toile par les agences d'État.

6

En définitive, ces différents contextes nationaux apparaissent comme autant de variations autour d'un même principe de contrôle d'une sphère publique en partie créée par l'État, non sans certaines ressemblances avec le modèle chinois ${ }^{1}$. Pour autant, l'ouvrage réfute tout fatalisme: comme le rappelle justement Bernard Formoso en conclusion, les difficultés rencontrées par les sociétés civiles dans ces pays ne résultent pas seulement de déterminismes culturels. Elles traduisent aussi le poids des clivages laissés en héritage par les colonisateurs européens et les réflexes contemporains d'élites conservatrices. L'un des grands intérêts de l'ouvrage réside dans sa capacité à montrer qu'en la matière, stagnation - au sens de "projet inconscient de conservation $»^{2}-$ ne vaut pas immobilisme: les tensions politiques actuelles constituent aussi des moments d'introspection durant lesquels s'inventent de nouvelles formes de mobilisations et de nouveaux projets de société.

\section{NOTES}

1. Cf. Michael Frolic, «State-Led Civil Society », in Timothy Brook \& Michael Frolic, eds, Civil Society in China, Armonk-New York-London, M. E. Sharpe, 1997 : 46-67.

2. Cf. Claude Lefort, Le Temps présent. Écrits, 1945-2005, Paris, Belin, 2007 : 342. 